\title{
La reforma siscentista de la Casa de la Universitat de la Ciutat de Mallorca
}

\author{
Concepció Bauçà de Mirabò Gralla \\ Centre d'Ensenyament Superior Alberta Giménez (adscrit a la Universitat Pontifícia Comillas) \\ cbauca@cesag.org
}

Recepció: 29/04/2020, Acceptació: 21/09/2020, Publicació: 28/12/2020

Resum

L'edifici de l'actual Ajuntament de Palma és fruit de la reforma que durant la segona meitat del segle Xvir reestructurà la llavors anomenada Casa de la Universitat, amb el fi de dotar-la de la representativitat necessària. La present investigació es basa en la recerca documental per aportar novetats sobre la forma com es desenvolupà el procés constructiu de la nova façana i la reconstrucció interior de l'immoble. El dit seguiment inclou la troballa d'evidències sobre els recursos que es valoraren i s'utilitzaren a l'hora d'oferir una imatge renovada de la institució municipal als ciutadans.

Paraules clau:

arquitectura; Ajuntament; barroc; Palma de Mallorca; segle xvII

Abstract

The I 7 th-century reform of the University House in the city of Mallorca

The building that serves as the current town hall of Palma de Mallorca is the result of a reform carried out in the second half of the 17 th century to restructure what was then known as the University House in order to lend it the representational character it required. This investigation is based on documentary research to provide new information on the process to construct the new façade and reconstruct the interior of the building, as well as evidence about the resources that were used to provide citizens a renewed image of this municipal institution.

Keywords:

architecture; town hall; Baroque; Palma de Mallorca; i 7 th century 
$\mathrm{L}$ 'edifici actual de l'Ajuntament de Palma reflecteix majoritàriament la reforma del segle XVII, que el convertí en un exemplar únic de l'arquitectura civil de les illes Balears (figura I). Els orígens de l'immoble situat a la plaça de les Corts com a Casa de la Universitat de la Ciutat i el Regne de Mallorca i com a seu del Gran i General Consell es retrotreuen a l'edat mitjana. El i 343 l'Hospital de Sant Andreu ubicat en aquell lloc començà a compartir espai amb el Consell de la Ciutat de Mallorca i amb el Gran i General Consell fins l'any I456, quan fou traslladat a un altre lloc. El i 506 aquell edifici ruïnós fou renovat. S'hi van ubicar la sala dels jurats en la planta baixa i la del Gran i General Consell en la superior. A final de la centúria s'ampliava la superfície ocupada per la Universitat, que durant el segle XVII anà reparant i decorant la casa, fins que el I649 inicià la profunda reestructuració que ens ocupa.

La present investigació es basa en la recerca documental realitzada per tal d'aportar novetats sobre aquella reforma, especialment sobre el plantejament del seu nou frontispici i dels espais interiors. Pretén introduir una visió més completa i integradora del procés de reconstrucció de l'edifici tenint-ne en compte noves dades. El dit seguiment permet comprendre millor com se'n triaren els artífexs, quines opcions es consideraren a l'hora de renovar la imatge del govern municipal $\mathrm{i}$ com se'n desenvolupà finalment $\mathrm{el}$ procés constructiu.

"Las casas de la ciudad son magníficas, aunque de mal gusto» ${ }^{1}$. Així descrivia José Vargas Ponce l'antiga Casa de la Universitat, convertida en Ajuntament de Palma des de i7r6. També els primers viatgers arribats a Mallorca en menysprearen l'estil classicista la primera meitat del segle XIX, a causa de l'admiració dominant en- vers l'edat mitjana, que tan transcendent resultà a l'illa. Jean-Joseph Bonaventure Laurens cità la volada com el millor de l'edifici i ja indicà que havia estat policromada i daurada, cosa que repetiren historiadors mallorquins com ara Antoni Furió i Joaquín M. Bover (figura 2)2 ${ }^{2}$. Pau Piferrer, Juan Cortada, Ramón Medel o Pascual Madoz en reflectiren unes prevencions similars $\mathrm{i}$ insistiren a destacar-ne el voladís. A final de la centúria, estrangers com ara Gaston Vuiller o Charles W. Wood i locals com ara Pere d'Alcàntara Penya seguiren el mateix discurs.

Una nova tendència pareix emanar de l'arxiduc Lluís Salvador, qui explicà l'Ajuntament com una de les millors cases de Ciutat, oferint-ne una descripció interior poc freqüent. Fins aquí cal remarcar certa confusió d'hipòtesis sobre la datació i l'autoria de l'immoble. No fou fins que va aparèixer el volum dedicat a les Illes Balears, de Josep Maria Quadrado i Pau Piferrer, que se'n documentà l'acabament per primera vegada el I680 i que se n'adjudicà el voladís al seu autor ${ }^{3}$.

A les acaballes d'aquella centúria sorgiren els primers escrits proteccionistes envers l'edifici, enfront del compromès projecte de reforma que l'Ajuntament havia encarregat el I 892 a l'arquitecte Manuel Chápuli. Un pic iniciat, el mateix Quadrado defensà la volada $i$ el vestíbul que es volien transformar enfront de la Real Academia de San Fernando. El mestre d'obres Bartomeu Ferrà, des de la Societat Arqueològica Lul-liana, encapçalà una campanya defensant la integritat d'aquelles parts, que considerà les més valuoses ${ }^{4}$. Finalment, l'incendi de I894 acabà destruint bona part de la planta baixa, cosa que, almenys, ens en deixà alguna descripció com a testimoni.

Durant la primera meitat del segle XX autors com Arthur Byne divulgaren l'Ajuntament com un dels millors casals de Ciutat, mentre la fa- 


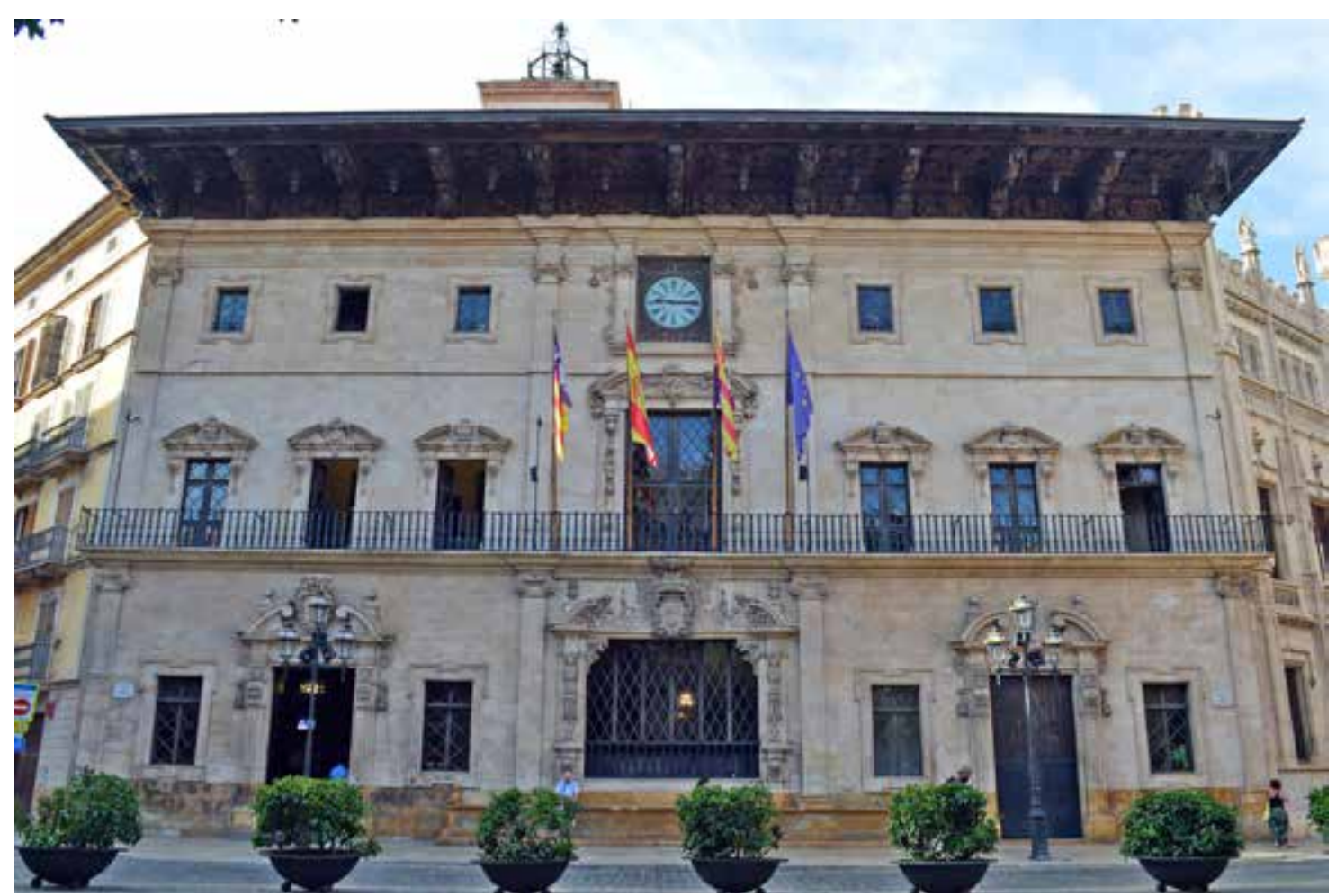

Figura 1.

Ajuntament de Palma. Foto: autora.

çana es reproduïa sobre postals, fullets i llibrets dedicats als primers turistes. Des de les fototípies de la casa Hauser i Menet fins a les guies illlustrades de Palma, la plaça de Cort es popularitzà com un lloc que calia visitar. I el I93 I la façana fou declarada Bé d'Interès Cultural amb categoria de monument ${ }^{5}$. A les portes del boom turístic, la guia de Joan Muntaner Bujosa, la guia Costa o els estudis sobre la ciutat de Diego $\mathrm{Za}$ forteza i Pedro Antonio Matheu explicaven la Casa Consistorial amb certa extensió.

No fou fins a la dècada de 1970 - amb l'inici dels estudis d'Història de l'Art a les Balearsquan l'edifici de Cort es començà a analitzar des del punt de vista estilístic gràcies a Santiago Sebastián. El definí com a resultat d'un italianisme hispanitzat mitjançant la influència aragonesa del voladís i en relacionà la façana amb l'obra d'un escultor. La seva visió assentà les bases dels estudis posteriors ${ }^{6}$.

Els dits estudis es reprengueren una dèca$\mathrm{da}$ després. Al llibre monogràfic sobre l'Ajuntament de Palma coordinat per Catalina Cantarellas - que constituí una fita essencial per conèixer l'edifici-, Mercè Gambús explicà els artífexs de l'obra $\mathrm{i}$ en reconstruí la seqüència constructiva a partir de la investigació documental'. Es tracta del punt de partida del present treball. D'altra banda, Cantarellas analitzà les modificacions contemporànies de l'edifici i el resultat que aquestes van oferir al segle XX. Estudià les polèmiques que l'envoltaren $i$ les reformes que acabaren per transformar-ne algunes zones fins arribar al producte que avui en coneixem. En aquest sentit, ens ha aportat informacions valuoses a l'hora de reconstruir aspectes concrets de la construcció siscentista ${ }^{8}$.

La recerca arxivística duta a terme aquesta vegada s'ha basat en les unitats documentals conservades a l'Arxiu del Regne de Mallorca, procedents de les dues institucions lligades a l'edifici de Cort. En primer lloc, la mateixa Universitat - que n'era titular - en generà una extensa informació, malgrat que gran part de les juntes dels jurats corresponents a l'època es perderen en l'incendi de l'Ajuntament ocorregut el I 894 . Així, resulta impossible il-lustrar el període que s'inicià el I649. En canvi, la sèrie Extraordinaris d'Universitat reuneix les juntes convocades pels jurats a fi de tractar temes especialment rellevants, entre els quals es troba la reforma que ens ocupa. En segon lloc, ens hem servit del fons de la Fortificació, perquè aquesta institució reial s'encarregà del finançament de la major part de les obres mitjançant el seu pressupost anual'.

La consulta dels dos fons citats permet obtenir una visió incompleta però representativa de la reforma siscentista de l'edifici. Aquest tema havia estat treballat ja bàsicament per Gambús. Ara, la troballa de documentació inèdita ens ha 


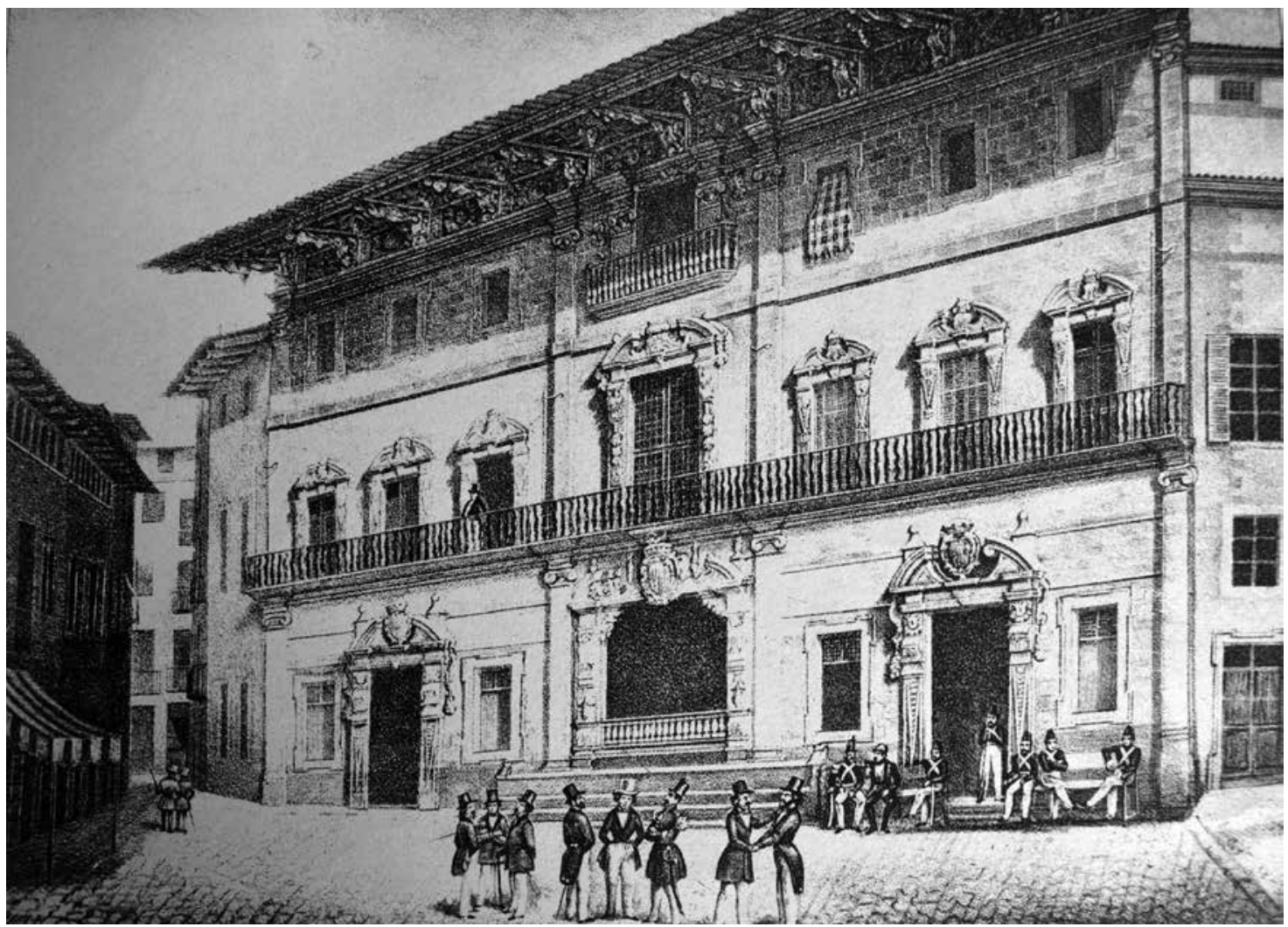

Figura 2.

Antonio Furió, Panorama óptico-histórico-artístico de las Islas Baleares, 1840.

permès conèixer detalls dels períodes constructius menys coneguts, així com establir noves hipòtesis sobre el plantejament i el desenvolupament de l'obra.

Quant a les fonts gràfiques, cal reconèixer la dificultat d'identificar algunes particularitats de l'edifici del sis-cents, ja que una part es va perdre en l'incendi i l'altra es reformà a final del segle XIX. Aquelles transformacions foren les que restaren més documentades mitjançant la imatge i per tant les que han arribat fins a l'actualitat. Només n'hem localitzat algunes reproduccions que mostren la façana, un enteixinat interior $\mathrm{i}$ un plànol de la distribució interna abans de ferhi els canvis vuitcentistes. N'hi ha un parell que es comenten al lloc corresponent.

\section{La reforma siscentista: El primer cos de la façana i els interiors de la planta baixa}

El I649 els jurats decidiren iniciar la reforma de la Casa de la Universitat, un conglomerat de construccions medievals arruïnat que s'intentava reparar des del principi de la centúria. Gambús detallà les passes que els dits representants seguiren per tal d'obtenir el finançament necessari, que finalment arribà del pressupost de la Fortificació, a la qual la mateixa Universitat contribuïa anualment ${ }^{10}$. No se'n conserva el llibre que devia documentar la traça de la nova façana, ni tampoc ens n'ha arribat el dibuix. $\mathrm{Pa}-$ reix que el responsable del disseny fou el sergent Vicenç Mut i Armengol, al front de les fortificacions del Regne ${ }^{11}$.

Segons l'autora citada, el frontis de Cort segueix l'esquema tradicional de les façanes dels casals mallorquins a partir de tres cossos decreixents, però hi afegeix elements propis del llenguatge classicista. Aquest llenguatge s'expressa en la tipologia de la façana retaule, es concreta en una retícula d'impostes i pilastres i hi incorpora un important desplegament decoratiu tallat sobre la pedra i la fusta de la volada. Gambús en destacà també l'eix de simetria central i el joc dels portals laterals, l'elecció del jònic com a ordre més adient per a un edifici municipal i l'ornamentació deutora del model italià, que utilitza motius procedents de la influència manierista i de la tradició dels retaules barrocs ${ }^{12}$.

Se sap que el primer cos fou aixecat entre I649 i I650, en una actuació dirigida pel picapedrer Pere Antoni Bauçà, mentre fou Joan Antoni Oms qui s'encarregà de tota la decoració tallada en pedra. Segons afirmava Marià Carbonell, aquest darrer fou l'escultor siscentista més important després de Jaume Blanquer, dominà el 
mercat artístic del segon terç del segle XVII i fou membre de la nissaga més coneguda $\mathrm{i}$ amb més continuïtat de Mallorca ${ }^{13}$. Treballà en l'àmbit de l'arquitectura, però sobretot dirigí i obrà retaules.

El primer cos està protagonitzat per dos grans portals d'accés i una tribuna central ${ }^{14}$ que se separen entre si per finestres. Aquelles importants obertures destaquen gràcies als frontons partits que les rematen, coronades pels grans escuts de la Universitat i el Regne de Mallorca. Es tracta d'un recurs freqüent a l'arquitectura civil, de fet les armes es poden relacionar amb unes altres de coetànies procedents del món de les fortificacions ${ }^{15}$. Però el més original és l'acumulació decorativa circumdant, tan poc habitual als edificis mallorquins de l'època. Està protagonitzada, entre altres elements, per suports amb estípits i antropomorfs, màscares monstruoses $i$ animals, cartrons retallats, motius auriculars $i$ poms de fruites que no només remeten a la tradició clàssica - en la seva accepció tardo-renaixentista-, sinó també i en concret al catàleg decoratiu de l'escultor Joan Antoni Oms. Tot plegat demostra el món dels retaules en el qual s'havia format ${ }^{16}$.

Un pic acabat el primer cos de la façana el I650, els estudis existents mostraven un buit documental fins al i665, poc abans de començar-se el segon ${ }^{17}$. Hom es demanava quines actuacions havien ocupat aquells quinze anys i per quina raó s'havia esperat tant a continuar-ne el frontis. Probablement les dificultats de finançament en foren el motiu principal, atès que la pedra de Santanyí emprada exigia una gran despesa econòmica. Durant aquell temps els esforços se centraren en la resta de l'edifici. Les obres que s'hi feren s'exposen a continuació seguint un criteri cronològic, per tal d'intentar reconstruir la seqüència constructiva en la mesura del que sigui possible.

L'any I653 s'establiren les condicions per acabar l'anomenat «enfront menor», del qual ja n'existia una part. Amb aquesta denominació hem d'entendre la realització d'una altra façana, per a la qual s'escriví un contracte a escarada molt detallat ${ }^{18}$. Les profundes transformacions patides per l'immoble ens impedeixen identificar-la i ubicar-la exactament avui, però se sap que connectava amb el frontis principal, que podria correspondre a la situada a la seva esquerra i que limitava amb el carrer de la Cadena.

La documentació reflecteix la construcció d'una façana secundària que s'havia d'acabar segons les pautes d'allò que ja es trobava construit. Simplificava els acabats i les despeses respecte a la principal, ja que la pedra de Llucmajor dista molt en qualitat i preu respecte a la de Santanyí. Segons se'n dedueix, se n'havia de repetir els dos cossos i el porxo superior. Resulta significatiu el fet que el contracte demani substituir els «fines- tratges» del frontis de Cort per finestres - més petites -, i sembla que les redueix a dues en cada cos, incloent la decoració que s'havia de fer a partir de les mostres aportades. L'altura havia d'arribar al nivell de l'edifici existent i la documentació especificava la construcció dels pilars necessaris per sostenir el porxo, una cornisa $\mathrm{i}$ una nova teulada, així com la resta dels murs.

Les cent setanta-set lliures que el document destina a la construcció de l'enfront menor contrasten respecte a les més de mil que s'havien pagat tres anys abans al picapedrer del cos inferior de la façana major ${ }^{19}$. Havien de servir per fer un frontis secundari, però coherent. La necessitat «d'encaxalar» o enqueixalar ${ }^{20}$ la paret que l'unia amb la façana principal indica que s'hi havia de connectar. A més, es requeria l'aixecament dels murs perimetrals, de la teulada i completar la paret mitgera afegint-hi un portal tallat.

Sembla que l'obra es desenvolupà immediatament, atès que les pàgines següents del llibre enregistren treballadors, fiances i pagaments relacionables ${ }^{21}$.

Sobre la distribució interior, el contracte especifica la necessitat de conservar tot allò aprofitable de les parets existents mitjançant materials semblants. La casa comptava amb habitacles ruïnosos, cosa que en feia indispensable algunes reparacions. El text indica la continuació de la paret mitgera de pedra del Coll d'en Rabassa i l'obertura d'un portal tallat, a imitació d'un altre de decorat amb un escut daurat que donava accés a l'anomenada «segona estància». En aquest punt cal notar que el pedreny de Santanyí que es demanava implicava novament certa representativitat ${ }^{22}$, a part que facilitava la talla dels motius escultòrics.

El plànol de 1862 conservat a l'Arxiu Municipal de Palma és el més antic on es pot veure l'edifici siscentista abans de realitzar-hi les reformes vuitcentistes (figura 3). El primer aiguavés del pis inferior mostra com se succeien la sala de juntes, la tribuna, al seu darrere l'atri i el vestíbul petit. L'arxiduc Lluís Salvador encara va veure aquells portals repartits entre les primeres estances i el I 882 descriví com repetien l'escut de la ciutat i el Regne de Mallorca. Cità com algunes de les seves decoracions reflectien un origen gòtic, $\mathrm{i}$ unes altres, un de renaixentista:

Sobre la puerta [de la entrada] están el escudo de Palma con las barras de Aragón y el castillo, lo mismo que sobre las dos puertas que se abren en el vestíbulo y en medio, y enfrente de los mencionados existe un tercer escudo dorado, antiguo, rodeado de un marco también dorado. La puerta de la derecha corresponde a un hermoso portal de estilo Renacimiento con el escudo de Palma y ángeles sosteniendo una guirnalda en relieve. 


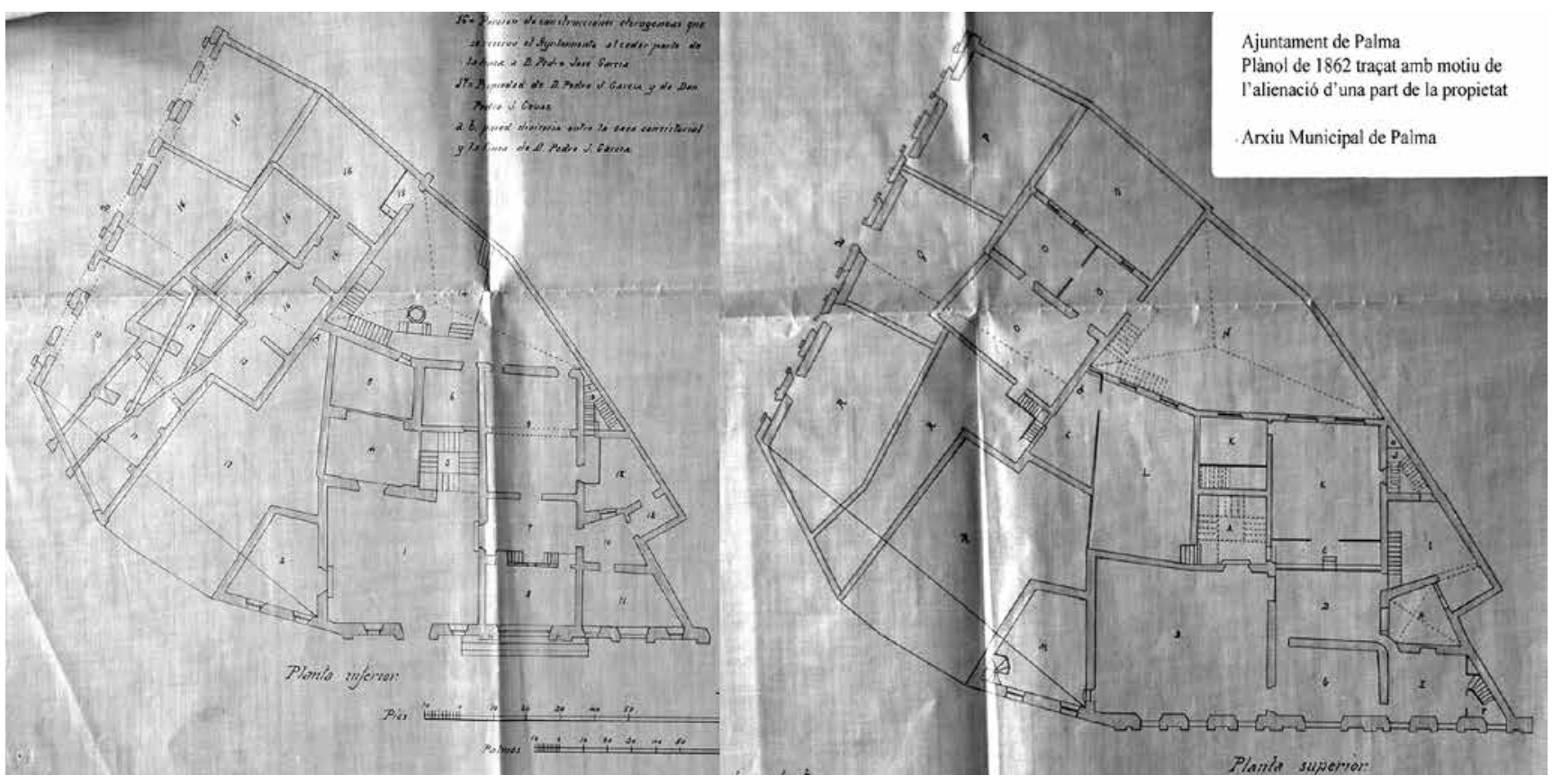

Hay también una inscripción muy antigua empotrada en la pared. Un arco rebajado con capitelles de follajes, otro precioso con adornos vegetales y un tercer arco con grotescos esculpidos. Las dos puertas de este portal muestran el escudo de la ciudad entre una ornamentación gótica dorada muy bella ${ }^{23}$.

Gambús relacionà aquells portals amb la reforma del sis-cents. Ara sabem, gràcies a la documentació aportada, que n'hi va haver un que fou tallat el 1653 pel picapedrer Bartomeu Ferrer i que imitava el model d'un altre d'anterior amb l'escut daurat, situat al costat. Tanmateix, la falta d'imatges d'aquells interiors i el fet que fossin destruits en l'incendi de I 894 en dificulta qualsevol valoració estilística. La seva pèrdua en motivà una nova descripció, feta ara per Bartomeu Ferrà:

También ha sido destruido por completo el notable escudo dorado que coronaba la puerta lateral del zaguán y el dintel y jambas del mismo vano aparecen quebrantadas por la acción del fuego; ¡Lástima que se hayan perdido los dos mejores escudos de armas de la ciudad! Uno de ellos había sido clave del templo de Santo Domingo, y otro estaba encuadrado en una cartela dorada, sobre la puerta que desde el gran zaguán daba paso lateral a la tribuna ${ }^{24}$.

Amb tot, podem concloure que la zona de recepció i reunió de la Casa de la Universitat estava decorada amb importants portals blasonats que reproduien els escuts de la Ciutat i del Regne i que repetien també les figures dels àngels. Així doncs, al segle XVII s'empraren els mateixos recursos a l'interior i a l'exterior de l'edifici per tal de recordar el patrocini de la institució.

Cal remarcar que el contracte obvia la sala de juntes i l'església medieval de Sant Andreu - en la segona crugia - utilitzada com a pròpia pels jurats, que la compartien amb la confraria del gremi dels ferrers. Així, no s'hi actuà. Quant a la segona, se sap que la Universitat s'encarregava de fer-ne el manteniment ${ }^{25}$ i que ja havia patit una modificació substancial. Segons estudiaren Catalina Cantarellas i Francesca Tugores, la construcció de la nova façana siscentista en degué escapçar una part ${ }^{26}$.

Tampoc s'hi cita cap actuació a l'escala quadrada situada al fons del vestíbul. Ja existia el I653, segons el dibuix que en féu Josep Gelabert, qui la descriví com «una escala qui balla dins un quadro tresade per el pla» ${ }^{27}$. Feta de pedra de Santanyí i amb prop de cinc metres de caixa, fou dibuixada per Bartomeu Ferrà, qui la pogué veure abans de ser destruïda: «A la casa de la Ciutat, vulgarment anomenada la Sala, molts d'anys degué durar aquella feixuga escala apuntalada que, ens figuram, mai degué desembarcar condreta al primer pis ni arribar, no essent per força, dalt del porxo ${ }^{28}$.

Després de les obres referides, la documentació emmudeix i els treballs no reapareixen fins al maig de I66I, quan es consolidà una estança nova construïda sobre l'arxiu per tal de protegir-lo. Se'n sap molt poc d'aquell espai que servia no 


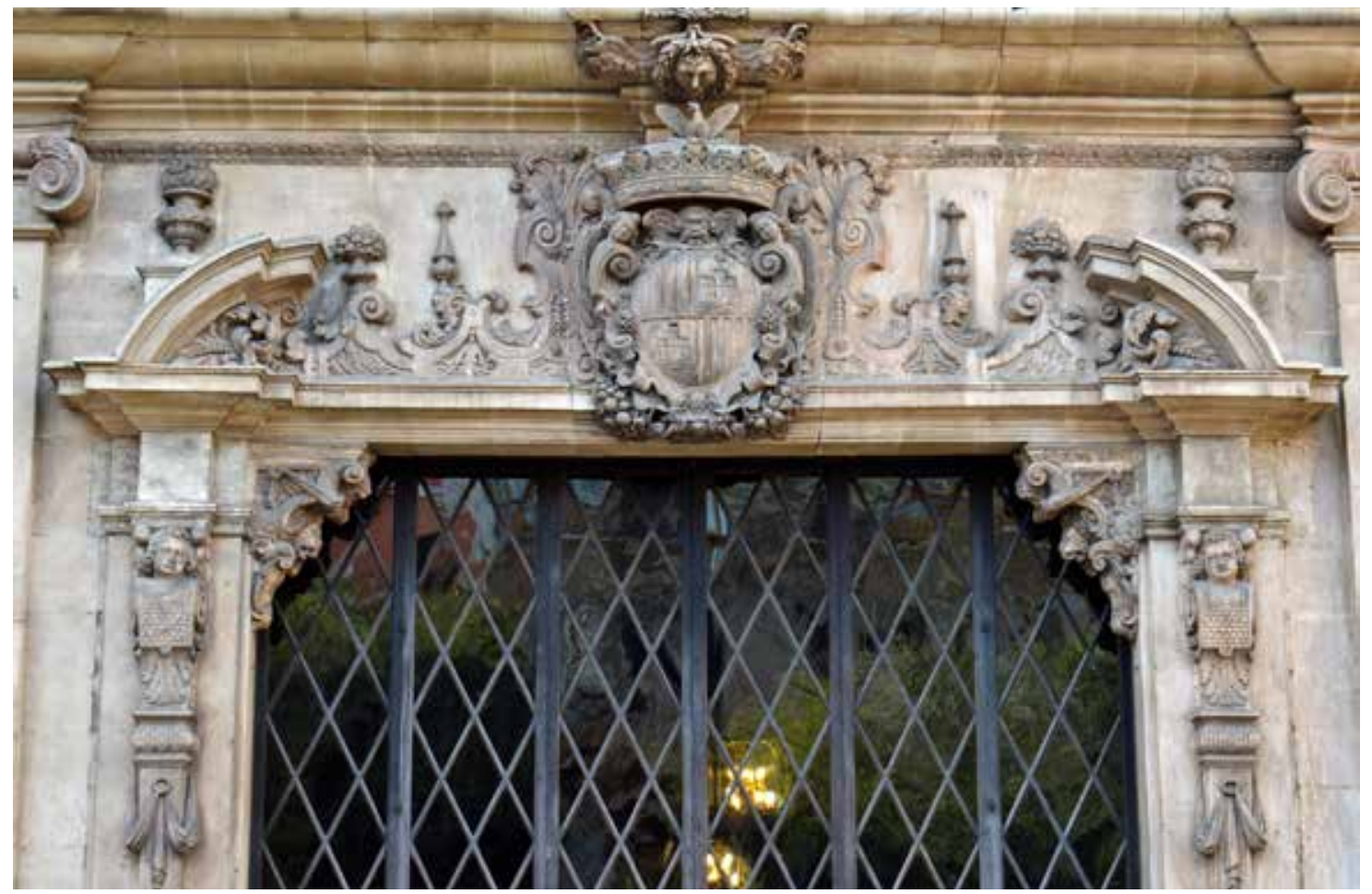

Figura 4.

Detall de la tribuna. Foto: autora.

sols per conservar la documentació de la Universitat, sinó també per guardar l'arca gòtica de les insaculacions, que servia per triar-ne els càrrecs ${ }^{29}$.

Dos anys després es treballava al pati interior, anomenat «de les sitges», on es trobaven els dipòsits amb les reserves de blat de la Universitat. Deu correspondre al que s'ubicava en la zona posterior, darrere l'oratori de Sant Andreu. Tenia una planta irregular, a causa de les particularitats del solar, i una cisterna que devia connectar amb l'aljub de l'edifici. El 8 de maig de 1663 es publicà un contracte per tal de cobrir-lo. En un extens plec de condicions s'hi detallava la construcció d'un sistema de canonades, vint-i-set columnes d'un màxim de nou metres d'alçada, catorze finestres «ratxades» - amb reixes - i una teulada. Dotze dies després s'atorgava l'escarada al picapedrer Bartomeu Calafat per quasi dos mil lliures. L'obra durà sis mesos, segons la visura feta el 2 I de desembre, que determinà que les columnes aixecades no complien l'altura prevista ${ }^{30}$.

\section{El segon cos de la façana,} els sostres de la planta baixa i els interiors de la planta noble

El i665 una reial ordre manà pagar als jurats mil lliures més a compte de la Fortificació per continuar les obres del frontis principal. L'onze d'abril de l'any següent una junta de mestres visurava l'obra, per tal de determinar si es podia seguir amb la construcció. Durant aquell estiu es pagà a distints picapedrers la cornisa de la planta baixa i l'assentament del segons cos, corresponent a la planta noble de l'edifici ${ }^{31}$.

Així i tot, la qüestió no devia estar clara, ja que el 3 I d'octubre d'aquell mateix any de i 666 es produí una nova inspecció que se centrà en la tribuna central (figura 4). El document reflecteix el temor que una obertura tan gran com aquella pogués aguantar el pes del segon pis $^{32}$. Després del veredicte positiu dels experts, es construí el segon cos de la façana dirigit pel picapedrer Bartomeu Calafat, que ja havia dut a terme l'obra del pati. Durant aquell any, Calafat aniria cobrant les mil lliures donades pel rei, juntament amb els trencadors de pedra Damià Tomàs i Juan Ferrer; el conrador Joan Planes, que transportà el pedreny de Santanyí; el guixer Miquel Antelm, i l'escultor Antoni Carbonell ${ }^{33}$.

Gambús cità els responsables de cada part de l'obra i concretà aquesta etapa entre el setembre de 1666 i el maig de i667, remarcant la construcció de dos arcs interiors als extrems de l'edifici i la retirada d'escombraries. Entre tots, en destacà l'autor dels treballs decoratius que ompliren el segon pis de la façana i en féu una ressenya biogràfica ${ }^{34}$.

Es tracta del conegut escultor Antoni Carbonell, que passà a substituir el difunt Joan Antoni Oms, qui probablement hauria estat el seu mestre. Cal assenyalar que Carbonell havia 


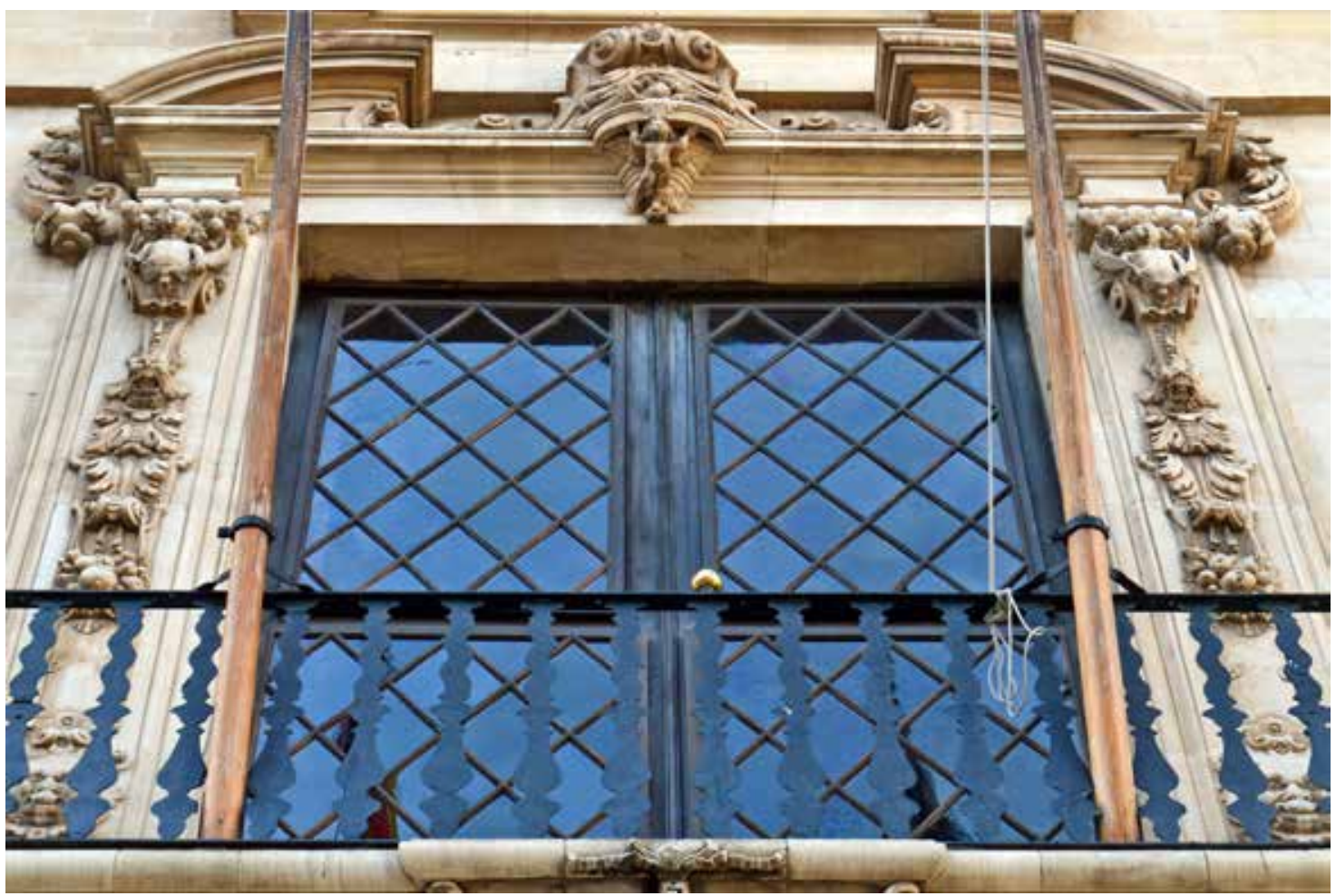

Figura 5.

Portal central del pis noble. Foto: autora.

estat requerit per treballar en la galeria exterior del Consolat de Mar juntament amb Pere Joan Pinya el i665 i que la seva experiència es materialitzà en moltes altres obres de decoració arquitectònica $\mathrm{i}$ en retaules ${ }^{35}$.

El seu estil -deutor d'Oms - simplificà al segon cos de Cort l'exuberància decorativa que havia desplegat el primer, limitant-ne els relleus que ornaren els set portals oberts a la gran balconada correguda. Aquesta es convertí en la principal protagonista del pis noble, atès que responia a funcions representatives $i$ constituia la tribuna d'honor de les autoritats ciutadanes durant tot tipus d'actes i festivitats.

A més, Carbonell restringí els motius antropomorfs al portal central, flanquejat ara per pilastres decorades amb grotescs i àngels estípits. Està coronat amb un frontó partit rematat al centre per un relleu amb motius auriculars, fullatge $i$ un pom de fruites que descansen en una peanya suportada per un àngel (figura 5 ). L'arxiu de l'antiga Universitat ha revelat una novetat interessant respecte al dit portal.

El i 8 de maig de i667, quan els treballs del segon cos ja devien haver acabat, els jurats volgueren realitzar alguns canvis en el disseny, que havien restat inèdits fins ara. Decidiren afegir una decoració de fullatges en les obertures de la planta noble i demanaren a l'escultor Antoni Carbonell que tallés un conjunt religiós per culminar-ne el portal central, amb la qual cosa se'n modificà la traça inicial. El conjunt estava format per la figura de la Immaculada, acompanyada del beat Ramon Llull i la beata Catalina Tomàs. El document detalla inclús la visura feta a l'obra acabada, que avui no es conserva al seu $\operatorname{lloc}^{36}$.

Quina fou la raó d'aquella demanda? La Universitat exercí una labor propagandística molt important envers els personatges citats, que es pot resseguir en la documentació de l'època. En primer lloc, la devoció a la Immaculada Concepció, promoguda per la Corona espanyola, s'havia estès a Mallorca gràcies al bisbe Vich y Manrique. Al segle XVII s'intensificà i trobà ressò en els jurats de Ciutat, els quals el I629 proclamaren «[...] que est fidelíssim Regne de Mallorca té rebut de la Verge Maria Sacratísima per estar baix lo seu amparo y protecció y la singular devoció que té a la confesió de la Immaculada Concepció» ${ }^{37}$. La defensa de la Immaculada acabà de consolidar-se a l'illa quan el Gran i General Consell l'elegí patrona del Regne el I643, poc abans de ser proclamada com a tal a la resta d'Espanya. Però els orígens de tanta devoció per part dels mallorquins es retrotreuen a l'edat mitjana, amb Ramon Llull com un dels seus impulsors.

Quant al savi, està documentat que la Universitat adquirí les seves obres a mitjan segle XVII i que cada any els jurats elegien a la sala de juntes els obrers que s'encarregarien de solemnitzar la seva festa. Enfront de les polèmiques creixents 
i les manifestacions antilul-listes que durant la segona meitat de la centúria en posaren en perill la devoció, pressionaren a favor de la causa de la beatificació i li mantingueren el suport fins a les darreries del sis-cents, defensant la seva figura contra totes les agressions que patí.

De forma semblant, el Gran i General Consell havia promogut la causa de beatificació de Caterina Thomàs el I625, per a la qual els jurats feren gestions diplomàtiques $\mathrm{i}$ acordaren recaptacions especials des de i664. L'arxiu recull les quantitats periòdiques designades a la seva provisió $\mathrm{i}$ el nomenament de protectors per tal d'afavorir-la ${ }^{38}$. Els esforços invertits resultaren profitosos i el i67i l'avanç de la causa se celebraria a Ciutat, amb una gran cavalcada patrocinada per la Universitat ${ }^{39}$.

Així doncs, la tríada formada pels dos mallorquins i la Immaculada, que havia de culminar la façana de Cort, respon a una dèria pròpia dels jurats. La documentació indica que acabà concretant-se en pedra, ja que l'acta de la junta citada detalla la confecció de la traça, el procés de realització, la talla de l'escultor i el preu final que s'estipulà. Les cent quaranta-quatre lliures que costà resulten una quantitat molt elevada que possiblement es pot explicar a causa d'un acabat policromat o daurat. Aquesta possibilitat seria factible des del moment que uns altres elements del frontis de Cort compartien les esmentades tècniques. Però avui dia, amb l'obra perduda, no en podem assegurar res.

Visuraren el conjunt escultòric artistes coneguts del gremi local, que han estat estudiats per Marià Carbonell: Damià Creuades fou el deixeble més directe de Joan Antoni Oms i a Jaume Ballester el suposà relacionat amb el seu entorn o amb el de Jaume Blanquer. En aquest darrer taller es podria haver format també Pere Joan Pinya. Finalment, trobam Gabriel Torres, a qui Carbonell ubica en la tradició blanqueriana i que mantenia una relació d'amistat amb Joan Antoni $\mathrm{Oms}^{40}$. En definitiva, es tracta d'escultors propers i relacionats amb l'edifici de Cort, ja que la majoria foren membres o coneguts del taller d'Oms. Entre tots en destaca Torres, perquè acabaria essent el responsable de tallar la volada de fusta que culminà la façana.

Resulta difícil valorar fins a quin punt el conjunt escultòric descrit hagués afectat la percepció actual de la façana. D’una banda, hagués emfatitzat l'eix axial marcat per les tres obertures centrals superposades que la presidien, abans de les modificacions decimonòniques. Però, sobretot, n'hagués modificat el significat, amb la qual cosa constituiria una escenografia de caràcter propagandístic envers la causa dels dos beats i de la Immaculada, que tant defensava la Universitat.
Aquelles devocions calaren profundament en la societat mallorquina de l'edat moderna i es materialitzaren en nombroses obres artístiques durant el sis-cents. De fet, i com ja apuntà Miquela Sacarès, l'associació entre la Beata i Ramon Llull es consolidà en aquella època, quan començaren a formar una parella usual iconogràficament parlant ${ }^{41}$.

Certament, el remat central actual sembla senzill per coronar el portal principal del pis noble. Al nostre parer, resulta comprensible la voluntat dels jurats, desitjosos d'atorgar-li una temàtica pròpia, influent i premeditada. Però el conjunt documentat no apareix als gravats de la primera meitat del segle $\mathrm{XIX}^{42}$, $\mathrm{i}$ avui la factura de la decoració existent es relaciona perfectament amb els motius que l'envolten. No pareix que s'hi hagi afegit posteriorment. Tal volta, les tres figures no s'hi installlaren mai.

Tornant als documents, l'arxiu es limita a enregistrar el dia 26 de maig d'aquell any de 1667 el pagament de distintes visures de la façana ${ }^{43}$. El frontis s'havia reforçat amb un arc i finalment els dos cossos restaven llests per prosseguir l'obra a l'interior del segon pis. Això i un ambient general d'estalvi econòmic degué determinar que les mil lliures designades pel rei a la reparació de la casa es reduïsin fins a sis-centes a partir del mes de juliol de i667. L'ordre especificava que el fet de sobrepassar la dita xifra comportaria pagaments personals a càrrec dels jurats ${ }^{44}$.

Les passes següents tenen a veure amb l'habilitació i la renovació dels interiors. La construcció d'una nova arca de les insaculacions per substituir la gòtica i del gran enteixinat de la sala dels jurats que l'havia d'embolcallar constitueixen el proper capítol. Es tracta d'una renovació marcada per una clara voluntat representativa. L'enteixinat es començà l'estiu de I669 i s'acabà durant el següent. Cobria una superfície de dotze metres de llarg per deu metres d'ample amb cassetons i estava decorat amb florons penjants i mènsules laterals tallades. Fou dibuixat per Bartomeu Ferrà i va desaparèixer durant l'incendi de final del segle $\mathrm{XIX}^{45}$. Posteriorment ha estat descrit i recentment l'hem interpretat en una investigació que actualment es troba en premsa $^{46}$.

Pensam que possiblement en la mateixa època es degueren construir dos enteixinats més petits, també de llenyam vermell, que cobriren el tram interior de la tribuna i la sala superior, coneguda com el consistori petit:

En el mismo palacio Municipal quedan, entre otros, dos techos artísticos muy notables por la sencillez de su molduraje, que forma combinaciones poligonales de bello y severo efecto; uno de ellos corresponde al tramo 
central de lo que fué tribuna, en planta baja, y el otro á la pieza superpuesta, en piso principal, llamada Consistorio pequeño, hoy aneja al despacho del Sr. Alcalde. Ambos son de madera de pino rojo y se hallan bien conservados $^{47}$.

Al nostre parer, tots formarien part d'un mateix projecte, basat en la fusta, que ennoblí els principals interiors seguint el programa decoratiu desenvolupat sobre la façana.

Cal recordar que el sistema de l'enteixinat amb cassetons no era nou. Havia arribat a $\mathrm{Ma}-$ llorca al segle XVI amb exemples com el de la Casa de l'Almoina i es continuava utilitzant per cobrir estances representatives d'edificis importants. Els més propers en el temps són el de la sala capitular del Consolat de Mar i el de la galeria contigua, que acabava en un original voladís de fusta. En aquest punt, cal recordar la participació dels escultors Antoni Carbonell i Pere Joan Pinya en aquell espai ${ }^{48}$.

Els artífexs del sostre de la sala dels jurats foren uns altres: Jeroni Oms, a qui el i 4 de juny de 1669 es compraren revoltons, jàsseres i els capitells que havien de rematar-les ${ }^{49}$ (pensam que es tracta d'un membre de la nissaga dels Oms, però actualment desconeixem quin parentiu tenia amb Joan Antoni, el mestre de la façana); un any després, el 6 de juny, es contractà el fuster Tomàs Juan per fer-ne el cassetonat ${ }^{50}$, i pel setembre s'hi afegí l'escultor Tomàs Seguí, per acabar-ne el fris perimetral que n'havia de delimitar tot el conjunt.

Just després se signava amb el fuster Antoni Vicens el contracte dels materials que servirien per pavimentar el pis immediatament superior. Aquest sòl corresponia al saló de sessions del Gran i General Consell. Vicens havia d'entregar cinquanta-sis dotzenes de mitjans ${ }^{51}$. Es tracta de peces rectangulars de pedra de Santanyí, de gruixa relativament prima, que servien per pavimentar els espais interiors d'edificis amb certa entitat. Aquest aspecte sumat al pedreny dels portals $\mathrm{i}$ als enteixinats de fusta permet comprendre fins a quin punt la Universitat dotà les seves sales de riquesa i representativitat.

Un pic acabat el paviment, el 7 de juliol de I67I, una junta de picapedrers decidí de quina forma s'havia de concretar l'alçat de la sala ${ }^{52}$. Les indicacions reflecteixen com s'havia de resoldre la construcció de l'estança i semblen precisar certa traducció de la configuració exterior de la façana, en detallar l'existència de pilastres. A més, resulta interessant que l'altura fos estipulada pels jurats en quaranta pams, després de les indicacions dels experts que havien determinat inicialment que en fes quaranta-dos. Sobre la sala se citen les botigues, és a dir, la planta superior o porxo que cul- minà l'edifici. I entre els picapedrers convocats destaquen Antoni Antelm i Bernat Cabrer, que ja havien acudit a la visura feta el i 666 per comprovar la seguretat de la tribuna.

\section{El tercer cos de la façana, els porxos i el voladís}

Una notícia inèdita indica com, el 2 d'agost de I67I, el picapedrer Bartomeu Calafat aconseguí una nova escarada per treballar l'enfront. L'obra es degué dur a terme entre aquella data i el i 8 de maig següent, quan es pagà un pic realitzada la visura corresponent. Es refereix al pagament del tercer i darrer cos de la façana ${ }^{53}$. Costà set-centes devuit lliures, menys que l'anterior a causa de les mesures inferiors que presentava. Estava protagonitzat per sis finestres emmarcades per requadres, que originàriament flanquejaven un portal central - envoltat per pilastres culminades amb capitells jònics - rematat per un petit balcó ${ }^{54}$.

En aquest cas, el document no esmenta cap escultor; fou el picapedrer qui dugué a terme íntegrament l'obra, a causa de l'absència de talla decorativa. El sentit decreixent del frontis de pedra arriba aquí a la màxima simplicitat. Segons es desprèn, l'obra s'hauria acabat a mitjan I672, quan restà llesta per rebre la coberta.

A partir de llavors es degué iniciar l'important voladís de fusta treballat per l'escultor Gabriel Torres que culminà la façana i que era sostingut per un complex entramat interior de suport que encara es conserva als porxos. Amb quasi quatre metres d'amplària, la volada resulta inèdita a Espanya, gràcies a les grans figures que sembla que sustentin la coberta representant atlants i cariàtides entre cassetons, penjants i mascarons (figura 6).

Com a novetat $\mathrm{i}$ tenint en compte les dades anteriors, s'ha de precisar la construcció de tot el conjunt entre i672 i I 680, quan en tingué lloc la visura final ${ }^{55}$. Sembla que l'any I673 l'obra es trobava avançada, perquè fou quan s'hi installaren els plafons del fris, segons una inscripció descoberta per Elvira González als porxos ${ }^{56}$. Amb tot, no hem pogut trobar cap documentació referent a això.

Avui dia no existeix cap interpretació precisa sobre el conjunt de la volada i els seus personatges. Per part nostra hem relacionat el ràfec de Cort amb la resta de l'edifici i hem tractat d'identificar els precedents d'aquesta peça tan original al context de l'arquitectura mallorquina, en una investigació que avui es troba en procés de publicació ${ }^{57}$.

En síntesi, pensam que podria haver interpretat un model anterior existent a Ciutat des del segle XVI: el de la volada de la Casa de l'Al- 


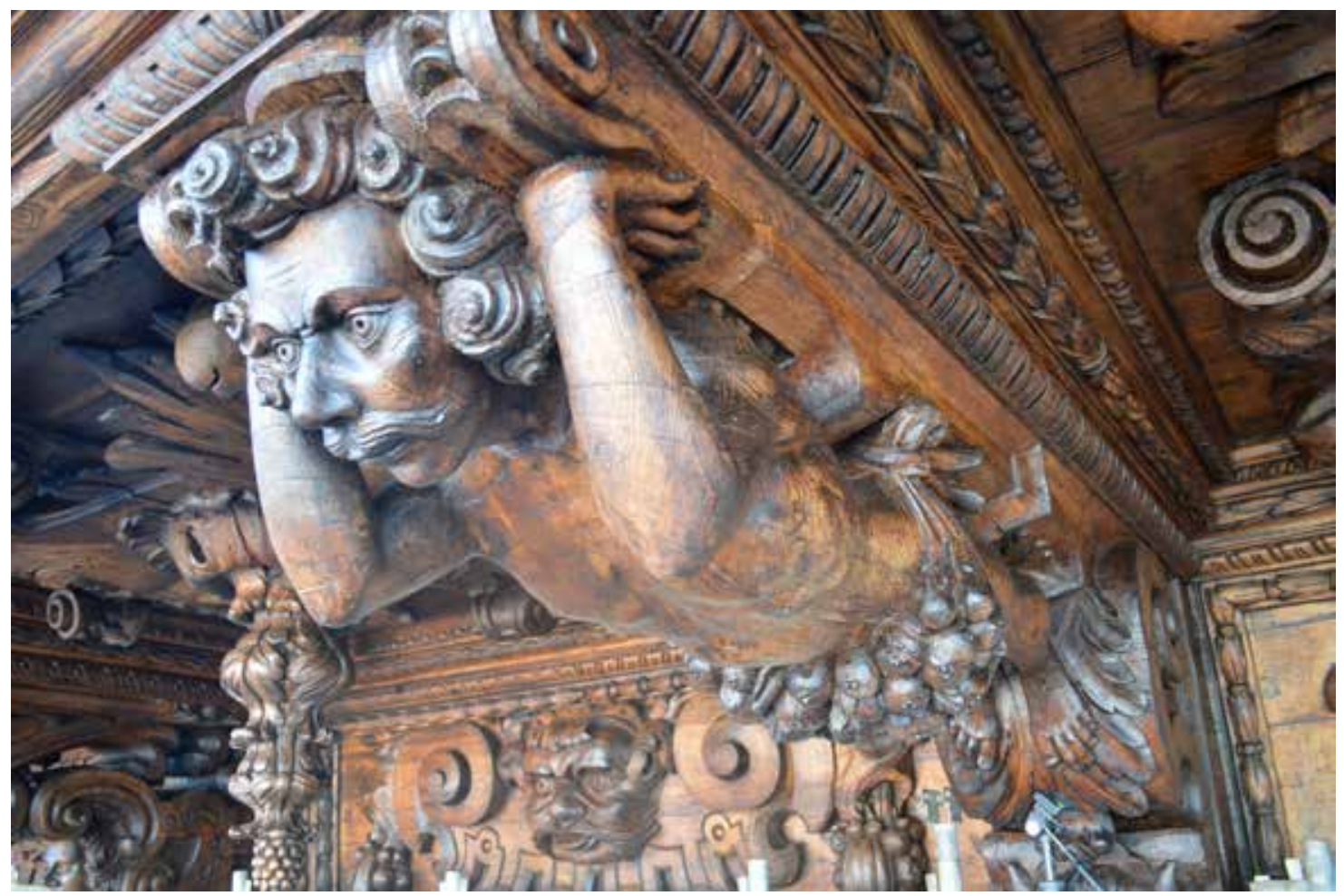

Figura 6.

Detall de la volada. Foto: autora.

moina, avui desapareguda. Molt desenvolupada, comptava amb figures d'àngels tallats i també es projectà per protegir el balcó corregut que en domina la façan $a^{58}$. Probablement a Cort, els atlants, les cariàtides i les màscares subratllaren el caràcter civil de l'edifici i alhora el seu compromís amb l'adscripció classicista i, per tant, amb l'arquitectura més culta. Per a fer-los, Gabriel Torres s'inspirà en el programa decoratiu d'influència tardo-renaixentista desplegat en pedra al cos inferior per Joan Antoni Oms, però el materialitzà mitjançant la rotunditat del sentit volumètric $i$ la tècnica pròpies del seu temps.

\section{Conclusió}

El procés de reforma que es desenvolupà entre I649 i i680 convertí la Casa de la Universitat en la més important i representativa de les construccions ciutadanes. Ho féu partint d'un edifici antic $i$ obsolet que s'intentà adequar a la nova imatge requerida per la institució, gràcies a les obres que s'hi desenvoluparen en tres fases, segurament allargades per les dificultats de finançament. Aquestes restarien definides així:

- Primer cos de la façana i interiors de la planta baixa (I649-I665).

- Segon cos de la façana, sostres de la planta baixa $\mathrm{i}$ interiors de la planta noble (I666-167I).
- Tercer cos de la façana, porxos i voladís (I67I-I680).

Com ja s'ha dit, el canvi més transcendental l'hi aportà el nou frontispici, summament original per al context mallorquí de l'època. Reuní la grandiositat d'una obra classicista dissenyada i sufragada des de l'àmbit de les fortificacions, l'execució tècnica dels picapedrers mallorquins i el tractament plàstic d'un petit grup d'escultors, encapçalats per Joan Antoni Oms ${ }^{59}$. La seva aportació decorativa acabà constituint una absoluta novetat respecte a l'austeritat de les construccions ciutadanes precedents.

Des del punt de vista simbòlic, pensam que el frontis constitueix una crida conscient a la representativitat que pretenia assolir la Universitat. Ho demostren els distints elements i recursos citats, però també la intenció novament documentada, de convertir-lo en un focus d'influència ideològica. Així s'explica que quan l'obra es trobava al lloc més destacat, és a dir, al balcó principal del pis noble, pensat en termes de representació, els jurats volguessin atorgar-li un sentit encara més concret. El conjunt escultòric format per la Immaculada i els dos beats mallorquins - que tant anhelaven - l'havia de presidir. Sabem que es tallà en pedra, però no tenim proves que s'hi arribàs a instal.lar. Si hagués estat així, el significat institucional de l'edi- 
fici s'hauria enriquit amb la reivindicació de les glòries pròpies, que tants esforços costaren als jurats. En definitiva, havien desplegat una gran pantalla escenogràfica i propagandística enfront dels ulls dels ciutadans.

Finalment, el discurs culte - oscilllant entre les influències tardo-renaixentistes $\mathrm{i}$ barroques que desenvoluparen els relleus arquitectònics culminà en una volada de fusta única en el seu gènere en tot l'àmbit espanyol. Els grandiosos atlants $\mathrm{i}$ cariàtides que mostra subratllen encara el deute classicista i el caràcter civil de l'edifici, però també fan palesos el poder i la versatilitat assolits pels escultors de la Mallorca siscentista, que Joan Antoni Oms havia anunciat al cos inferior.

Al mateix temps, la documentació confirma l'important paper dels picapedrers en l'aspecte constructiu de l'obra de Cort, que s'evidencia més a mesura que els escultors desapareixen. Això ocorre al tercer cos de la façana principal, al frontis secundari o en els treballs que afectaren els interiors i el pati de les sitges. També s'aprecia en les constants visures que realitzaren a fi d'aclarir la viabilitat de cada part. Se'n poden ressaltar dues: la realitzada en I666 sobre la tribuna central i la darrera, en I680, sobre el voladís.

Quant als interiors, s'ha pogut documentar com s'anaren reparant i reformant a mesura que s'aixecaven els cossos de la façana. S'aprofitaren les construccions existents completant-ne el que era necessari, s'adequaren les instal-lacions relacionades amb les funcions quotidianes al pati $i$ es concentraren els esforços a reformar-ne les estances més significatives. Al pis inferior s'ennoblí la sala dels jurats amb un important enteixinat de fusta, que es repetí en la tribuna i es tallà un nou portal blasonat. Al pis noble el saló de sessions del Consell es pavimentà i s'aixecà també amb grans despeses $\mathrm{i}$ un altre enteixinat degué cobrir el consistori petit. Malgrat que aquells espais no s'hagin conservat, les fonts documentals demostren l'esforç econòmic que s'invertí a favor de la imatge de la institució.

A més, cal destacar el sentit de continuïtat que tots aquells elements guardaren respecte a la nova façana. La dita unitat es reflecteix en la repetició dels materials emprats, però també en la de motius decoratius com els àngels, les màscares o els escuts que culminaren els portals. Igualment, es veu en la participació dels mateixos mestres o inclús en la d'altres que hi estaven relacionats. Tot plegat degué culminar el I680, quan, després de poc més de trenta anys, a la fi es donà per acabada la reforma que atorgà una imatge renovada $\mathrm{i}$ altament representativa a la Casa de la Universitat. 


\section{Apèndix documental}

\section{Document I}

Contracte a escarada amb el picapedrer Bartomeu Ferrer per acabar el frontis secundari de la Casa de la Universitat I 8 de juliol de 1653

ARM, AH EU 72, 165 I-1654, f. I $56 \mathrm{v} .-157 v$.

Qualsevol mestre de picapedrer qui vulla emprendre en fer per scarada en acabar y fer el enfront menor de la Casa de la Universitat, lo qual stà comensat de pedra Llucmajor, tenint obligatió de fer altras dos finestras conforme lo albarà y per çò diguey qui dir si voldria, ques lliurarà a qui per manco lo farà.

Primo per pacte que el qui empendrà dita scarada tindrà obligatió de continuar dit enfront de la matexa manera stà comensat, posant entre los pendents los brosench ${ }^{60}$ saran necessaris; en que dita paret vaja lligada conforme lo art demane. Més per pacte que dit scarador tindrà obligatió de pujar dit enfront fins al livell de la taulada stà feta de la casa de dita Universitat; y per pacte que tota la altària dels finestratjes haja de esser més alta de dita teulada.

Més per pacte, que enlloch de finestratjes, no tindrà obligatió dit scarador de fer més de dos finestras en los adornos se li enseñaran en una trassa o se li diran de paraula; tenint obligatió dit escarador de fer una gornissata en la diffinitió de dit enfront, allà ahont san de carregar los capitells de la exida del porxo.

Més per pacte que dit scarador tindrà obligatió de fer a dit enfront dos finestras de sobre dos stan fetas en lo matex adorno, exceptat que ha de esser més grans, y de pacte que ditas dos finestras se li donaran la pedra ques trobarà picada, tant per lo dafora com per los revols, de la matexa manera ques trobarà el die del lliuram.

Més per pacte que dit scarador tindrà obligatió de les tres parets que quedan, les haja de solar de mitja pedra y pujarlas fins al llivell de los més alt sòtil, de pedra y morter: y tindra obligatió, si acàs ditas parets stan, y es trova que stiguen gastadas, desfer fins allí ahont se trobarà sia bò per assentar; $y$ per si acàs la paret fos $y$ strobàs unbina, que dit scarador tinga obbligatió de desfer y fer a sas costas fins altària de vuyt palms, y si més se hagués de desfer, se li pagarà apart.

Més per pacte, que dit scarador tindrà obligatió de continuar un peu de pedra de Lluchmajor en una paret que ve de cap qui dividex lo enfront / enfront, de pedra de Santaní, junt en lo pilar plà; dexant los caxalbs a plom; per quant se determin pujar lo enfront major, ques puga encaxalar dita obra.

Més per pacte, que dit scarador tindrà obligatió de fer la teulada a sas costas de dita obra, pujant tots los pilas saran necessaris per a fermar los bastaxos de dits porxos.

Més per pacte que totas les parets saran sobre del últim sòtil, tindrà obligatió de entrevar entre pilar y pilar de paret de mitja pedra, solant de mitja pedra de plà la difinitió de ditas parets.
Més pacte que la paret mitjera de la casa de dita Universitat, se hajan de continuar de pedra del Coll den Rebassa conforme stà.

Més per pacte, que an al qui empendrà dita scarada, se li donarà tot lo pertret a peu de obra.

Més per pacte, que dit scarador ha de fer un portal en la paret mitjera per entrar en dits aposentos, de pedra de Santañí, conforme el que entra en la segona instàntia de la casa de dita Universitat, que té unas armas deuradas de sobre.

Més per pacte, se li donarà tota la pedra picada per dit portal, ques trobarà el die del lliurament.

Més per pacte, que a dit scarador se li donarà tots los lleñams, cordas y tests se hauran de menester per dita obra per fer bestiments y fuster per lo que sarà menester; que dit scarador no te obligatió de fer sinó lo que toca a las mans de picapedrer.

Més per pacte, que tota dita obra haja de esser visurada per instància dels magnífics senyors jurats, o la persona elegida per sus magnífics y trobant que dita obra no vaja conforme art, la puguen fer desfer y tornar fer a costas de dit scarador.

Més per pacte, que si acàs se lliuràs feyna, o se affigís de més de lo demunt specificat y dit, un a dret a laltre.

Més per pacte que el die que lliurarà dita scarada, nos puga llevar mà de ella en tota la pressa possible, fins y tant sia acabada.

Més per pacte, per dit scarador haja de donar bonas y suficients fianças a content de su señoria tots magnífics jurats tant per lo diner rebrà. Com si acàs la obra dins de un any y un die fes algun moviment. /

Més per pacte que a dit scarador se li donarà lo diner conforme saran los qui treballaran. I si acabada dita obra és creditor en niguna quantitat, se li pagarà en una partida.

A VI de juriol MDCLIII fonch lliurada la dita scara$\mathrm{da}$ ab los pactes demunt dits, per medi de mestre Melchior Alemany corrador de dita Universitat a mestre Bartomeu Ferrer picapedrer, per preu de cent y setante set lliuras; en les pagas demunt ditas. Y aquestas cosas present lo fit Ferrer, lo qual de grat ett. accepta lo lliurament a ell fet de dita scarada, y promet aquella fer y acabar en lo modo y forma contingut en lo determinat albarà, per lo qual obliga sos bens ett et large ett.

Testes Miquel Gelebert y Berd Alçamora ett.

\section{Document 2}

Visura feta a la tribuna central de la planta baixa 3 I d'octubre de I666

ARM, AH, EU 77, Extraordinaris Universitat I664I667, f. 242 v.

Convocats, congregats, y ajuntats sus señoria dels illustres y molt magnífics senyors Antoni Garriga ciutadà, Joan Moyà, Jaume Matheu Suñer mercaders y Jaume Llinàs forner jurats lo añy corrent de le Universitat, Ciutat y Regna de Mallorca, lloch sòlit y acustumat ett. han fet mi- 
rar a mestre Pera Antoni Baussà, Bernat Cabrer, Matheu Martí, Joan Mas y mestre Antoni Antelm tots picapadrers lo enfront de la Sala de la Universitat, y si el haver de proseguir (tatxat) la obra faria impediment lo arch de le finestre portal. Y mirada y reconeguda la obra y vista aquella juxta las concièncias digueren que bé es pot proseguir la dita obra sens ningun perill. De tot lo qual para que const ad eternam rei memoriam se ha continuat lo present acta per mi Joan Servera notari sacretari propi de la Universitat quare ett.

Testes ett Joan Marimon y Mi(quel) Binimelis.

\section{Document 3}

Acta de la junta de la Universitat que detalla la visura feta al conjunt escultòric religiós d'Antoni Carbonell destinat al pis noble de la façana

I 8 de maig de 1667

ARM, AH, EU 77, Extraordinaris Universitat 1664I 667 , f. 258 .

Convocats, congregats, y ajuntats su senyoria dels illustres y molt magnífichs senyors Salvador Oleza donsell, Hieroni Pont y Desmur, Antoni Garriga ciutadans, Joan Moyà, Jaume Matheu Suñer mercaders, y Jaume Llinàs forner, jurats lo corrent añy de le Universitat, Ciutat y Regne de Mallorca en la sala inferior de le Casa de le Juraria de dita Universitat, lloch sòlit, y acustumat hont ett.

Sabent $\mathrm{i}$ attanent que donaren escarada fer part del enfront de le Universitat a Bartomeu Calefat picapadrer conforme la trassa, y havent considerat després ésser convenient fer alguns fullatjes en las finestres y a la del mix fer una Nostra Senyora de Concepció, el Beato màrtir Ramon Llull y Sor Catherina Thomàs, conforme la trassa que se ha donat a mestre Antoni Carbonell sculptor. Y havent feta la obra dita su senyoria, ha manat ferle visurar a mestre Jaume Ballester, Gabriel Torres, Damià Creuades y Pera Joan Piña scultors, els quals han feta judicatura de cada cosa de per si, y conforme aquellas han adjudicat valer cent quaranta quatra lliuras, las quals ly prometen pagar de les mil lliuras que se Real Magestad ab se Real Carte mane que se gasten en la Casa de la Universitat. Y para que const ad eternam rei memoriam se ha continuat lo present acte per mi Joan Servera notari, secretari de la Universitat quare ett.

Testes ett. Magnifici Josephus Bassa, et Vicentius Matheu d. V. Dres.

\section{Document 4}

Acta de la junta de la Universitat detallant el pagament de visures fetes a la façana

26 de maig de 1667

ARM, EU, 77, Extraordinaris Universitat I664-ı667, f. $263 \mathrm{r}$.
Convocats, congregats y ajuntats su senyoria dels illustres y molt magnífichs senyors Salvador de Olesa donsell, Geroni Pont y Desmur, Antoni Garriga ciutadans, Joan Moyà, Jauma Matheu Suñer mercaders y Jauma Llinàs forner, jurats lo corrent añy de le Universitat, Ciutat y Regne de Mallorca, en la sala inferior de le Casa de la Juraria de dita Universitat, lloch sòlit y acustumat hont ett.

Sabent y attanent que mestre Baptista Monjo picapadrer, ab molts altres confrares del dit offici han fet differents visures en lo enfront de la Sala de le Universitat, y en particular per lo arch se ha resolt fer per conservar la obra, y en fer las ditas visuras han gastat molts temps y jornals, y ésser a rahó conforme que cada hu tinga lo que és seu y que dits menestrals no perden lo que podian guanyar, y axí bé mestre Pera Antoni Baussà / picapadrer ha rebut tot lo pedreny visurat y stimat aquell en differents, resolgueren donar çò es al dit monjo y sos companyons 5 L y al dit Baussà $3 \mathrm{~L}$ de diner ques gasta per la obra desta Universitat. De tot lo qual para que const ad eternam rei memoriam se ha continuat lo present acta per mi Joan Servera notari, sacretari de la Universitat quare ett.

Testes ett. Joseph Gonsales y Christòphol Barenguer.

\section{Document 5}

Acta de la junta de la Casa de la Universitat sobre el pagament del tercer cos de la façana al picapedrer Barthomeu Calafat

I 8 de maig de 1672

ARM, AH, EU 79, Extraordinaris Universitat I670I673, f. I75v.-I 76 r.

Convocats, congregats y ajuntats su señoria dels illustres y molt magnífichs señors Francisco de Oleza donsell, Pere Joan Font ciutadà, Joseph Amer mercader y Miquel Riera jerrer, jurats de la Universitat, Ciutat y Regne de Mallorca en la sala inferior de la Casa de la Juraria de dita Universitat, lloc sòlit y acustumat ha hont los negocis de aquella se ha acustumen tractar, diffinir y determinar per bé y utilitat de la dita Universitat, per effecte de resoldre la paga de la escarada ha fet mestre Barthomeu Calafat picapedrer en lo enfront de la sala de la Universitat que li fonch lliurada als 2 agost de I67I per setcentas y devuyt lliuras.

Y pres perer y fet mirar la dita escarada y obra dels magnífichs Miquel Nadal y Fuster Balle, don Farrando Moix y Francesch Armengol, y presos jurament mestre Antoni Antelm, sobreposats del offici de picapedrer, los quals havent fet llegir lo / alberà de la escarada de dita obra y reconeguda una y moltas vegades digueren ésser feta juxta las obligacions del acte, y perque const ad eternam rei memoriam se ha continuat lo present acte cuare ett.

Testes ett Gabriel Maure et Salvator Joan. 
1. J. Vargas Ponce (1787), Descripciones de las islas Pithiusas y Baleares, Madrid, Imprenta de la viuda de Ibarra, p. 34.

2. A. Furió Sastre (1840), Panorama óptico-bistórico-artístico de las Islas Baleares, Palma, Imprenta de Pedro José Gelabert, p. 56-57.

3. J. M. Quadrado i P. Piferrer (1950), Islas Baleares, Palma, Ed. Mallorquina de Francisco Pons, tom v, segona part, p. 144.

4. J. M. Quadrado (1892), «Manifestación de lo últimamente ocurrido en la Comisión Provincial de Monumentos», BSAL, 4, p. 275-280; B. Ferrà I Perelló (1892), Reconstrucción de la Casa Consistorial de Palma: Apuntes, Palma, Imp. de Felipe Guasp; «Voz de alerta», BSAL, 4 (1892), p. 223224; «Reconstrucción de la Casa Consistorial de Palma: Nuestro ante-proyecto», BSAL, 4 (1893), p. 295-301, i Transformaciones de la Casa Consistorial de Palma, Palma, Tipografía Católica Balear, 1895.

5. Decret de 3 de juny de 1931, RI-51-0000405 Ministerio de Cultura, Patrimonio Histórico, BOE 04/06/1931.

6. S. Sebastián López i A. Alonso Fernández (1973), Arquitectura mallorquina moderna y contemporánea, Palma, Estudio General Luliano, 46, p. 58-59, i «Arte», a Baleares, Madrid, Editorial Noguer, 1974, p. 244, 252.

7. M. Gambús SAIZ (1982), «Apuntes para el estudio históricoartístico de la fachada principal del Ayuntamiento de Palma», Estudis Baleàrics, 5, p. 117-151; M. Gambús Saiz i M. Massanet Gili (1987), Itinerarios arquitectónicos de las Islas Baleares, Palma, Conselleria d'Educació i Cultura Govern Balear, p. 41-42; M. Gambús SAIZ (1998), «La configuració arquitectònica de l'edifici: Des dels orígens al segle xvirI", a Ajuntament de Palma: Història, arquitectura $i$ cintat, coord. C. Cantarellas Camps, Palma, Ajuntament de Palma, p. 88-110; M. Gambús Saiz i P. Barceló (2014), Les arts a Mallorca entre els Austries i els Borbons, Palma, Lleonard Muntaner Ed., p. 24, i M. Gambús SAiz (2013), «Josep Gelabert: Mestre de pedra viva (1621-1668)», a J. GELABERT, Vertaderes traces de l'art de picapedrer, Palma, Edicions UIB, p. 112.

8. Volem agrair el seu suport en la present investigació. Vegeu C. Cantarellas Camps (1998), «Las transformaciones contemporáne- as", a Ajuntament de Palma: Història, arquitectura $i$ ciutat, coord. C. Cantarellas Camps, Palma, Ajuntament de Palma, p. 111-139; «Perspectiva historicoartística de l'edifici barroc de l'Ajuntament de Palma: El nucli de Cort i la rehabilitació de la darrera planta de l'aiguavés de la façana», a Memòria del Patrimoni Cultural. PC 10-11, Palma, Direcció Insular de Cultura i Patrimoni, 2010, p. 285 , i C. Cantarellas Camps i F. Tugores Truyol (2014), «A propòsit de l'església de San Andreu i de la capella de Sant Eloi a partir del segle XIV (Casa de la Universitat de Ciutat de Mallorca, Ajuntament de Palma)», $B S A L$, 70, p. 117-139.

9. Les referències documentals breus s'inclouen en el text, mentre que les més extenses s'han traslladat a l'apèndix final. Les transcripcions es fan sempre de forma literal, però se'n normalitzen els signes de puntuació, les majúscules i l'accentuació, per tal d'afavorir-ne la comprensió.

10. M. Gambús SAiz, «La configuració arquitectònica...», op. cit., p. 91-96.

11. Fou militar, concretament sergent major, i a més d'ostentar el títol de mestre major de fortificacions, ocupà el d'historiador del regne. M. Carbonell i Buades (2002), Art de cisell i de relleu: Escultura mallorquina del segle XVI, Palma, José J. de Olañeta, Editor, p. 35 , i M. Gambús SAIZ, «Josep Gelabert...», op. cit., p. 112.

12. M. Gambús SaIz, «La configuració arquitectònica...», op. cit., p. 104-106.

13. M. Carbonell i Buades, $A r t$ de cisell $i . .$. , op. cit., p. 94-99.

14. Es tracta del gran finestral central que no permetia l'accés des de defora, que servia com a marc d'alguns actes i que prenia rellevància en certes festes ciutadanes.

15. Exemples propers des del punt de vista formal són l'escut del regne que coronava la porta de Santa Caterina de Palma (1644), avui al pati d'armes del Palau de l'Almudaina; el conjunt de tres blasons del Castell de Sant Carles de Portopí (1663) o el del mur del Fortí (1670), avui a la costa de la Seu.

16. M. Gambús SAiz, «La configuració arquitectònica...», op. cit., p. 106.

17. Ibídem, p. 96-99.
18. Vegeu el document 1 en l'apèndix documental.

19. M. Gambús Saiz, «La configuració arquitectònica...», op. cit., p. 96.

20. Enqueixalar: enllaçar i travar les pedres d'una paret amb les d'una altra, endentant les pedres dins els queixals (Mallorca)». Diccionari Català-ValenciàBalear, Institut d'Estudis Catalans, $<$ https://dcvb.iec.cat/> [Consulta: 20 abril 2020].

21. ARM, AH, EU 72, 1651-1654, f. $157 \mathrm{v} .-158 \mathrm{v}$

22. «Un altre edifici important com és Cort, utilitza majoritàriament el pedreny per a la seva excepcional façana $i$, ja en època fora de l'àmbit d'aquest treball, per a la seva reforma interior». M. BALlester Julià (2017), Els materials de construcció a Mallorca: La documentació històrica (Segles $X I V-X V I I I)$, Palma de Mallorca, Lleonard Muntaner Ed., p. 121.

23. Transcrit i comentat a $M$. GAmbús SAIZ, «La configuració arquitectònica...», op. cit., p. 106107.

24. B. Ferrà i Perelló, Transformaciones de la Casa..., op. cit., p. 40,75 .

25. Ho demostra la visura que es manà fer a l'oratori el desembre de 1589. ARM, AH, EU 76 Extraordinaris Universitat 1661, f. 30.

26. Vegeu l'estudi de l'oratori a C. Cantarellas Camps i F. Tugores Truyol, «A propòsit de...», op. cit., p. 117-139.

27. J. Gelabert, Vertaderes traces..., op. cit., p. 369.

28. B. Ferrà i Perelló (1918), Ciutat ha seixanta anys 1850-1900, Palma, Miquel Font Editor, 1996. Vegeu també Arquitectura legal, Palma, Editorial Francisco Pons, 1959, p. 112. Recordant Ferrà, la citava Catalina Cantarellas, qui interpretà que devia constituir un element incrustat en l'estructura de l'edifici al segle xviI. C. CANTARELLAS CAMPS, «Las transformaciones...», op. cit., p. 120.

29. «[....] se ha comprat un tros de arbre de nau de que se ha fet dos jàceres per lo aposento se ha fet sobre lo archiu dels llibres de la taula / de la Universitat que per ser la cuberta baxa y la taula vana de ordinari se plovia sobre de dits libres». ARM, AH, EU 76, 
Extraordinaris Universitat 16611664, f. 5.

Sobre la ubicació, se sap que el 16 de gener de 1666 es congregaren el capità general del Regne i els jurats «[...] en lo archiu de la sala superior ahont se acustumen fer les insiculations, y extraxions per effecta de veurer, y regonexer la matricula dels insiculats en lo sach [...]». ARM,

AH, EU 77, Extraordinaris Universitat 1664-1667, f. 183v.

30. La gran extensió del document i el seu caràcter estrictament funcional ens obliga a transcriure'n només l'inici: «Albarà de escarada de cubrir las sitges. Tothom y tota persona qui vulla entendra en pendra la escarada el cubrir lo pati de las sitges de la Universitat, qualsevol sia lo escarader tindra obligatió fer dita obra ab los pactas y condicions siguents. Primo tendrà obligació fer vint y set columnes, nou per cada filada, y que las del mig hajan de ser de 44 palms de altària desde lo empedrat amunt [...]». ARM, AH, EU 76, Extraordinaris Universitat 1661-1664, f. 109. Vegeu també f. 109v.-110r. i 152r.

31. M. Gambús SAIZ, «La configuració arquitectònica...», op. cit., f. 99 .

32. Vegeu el document 2 en l'apèndix documental.

33. Vegeu els pagaments fets als distints professionals a ARM, RP 2541, Fortificació 1667, f. 1r., 3v., 4r., 7r., 9r., 11r., 15r.-15v., 17r., 19v., 27r., 29r., 33r., 36v., 41r.-41v. i 54r.

34. M. Gambús SAiz, «La configuració arquitectònica...», op. cit., p. 100.

35. Ibídem, p. 101; M. Gambús Saiz i M. Massanet Gili, Itinerarios arquitectónicos..., op. cit., p. 96, i M. Carbonell i Buades, Art de cisell..., op. cit., p. 109.

36. Vegeu el document 3 en l'apèndix documental.

37. B. BESTARD, «La Inmaculada Concepción, patrona del Reino de Mallorca», Diario de Mallorca (9 de desembre de 2006), <https:// www.diariodemallorca.es/palma/1377/inmaculada-concepcionpatrona-reino-mallorca/228752. html> [Consulta: 24 abril 2020].

38. Sobre les actuacions referides als dos personatges, vegeu ARM, AH, EU 73, 1654-1657, f. 62r.; ARM, AH, EU 74, Extraordinaris Universitat 1657-1659, f. 63r., i ARM, AH, EU 77, Extraordinaris Universitat 1664-1667, f. 48v. i 100r.

39. G. Carrió i Vives, A. R. Cano i Oléo i G. Llompart i Moragues (2006), El carro triomfal: Manifestacions populars a l'entorn de santa Caterina Tomàs, Palma, Consell de Mallorca, p. 31-32.

40. Aquestes filiacions i l'estudi detallat de cadascun dels escultors es poden consultar a M. CARBONell i Buades, Art de cisell..., op. cit., p. 99, 103-105, 107-108 i 111-113.

41. M. Sacarès Taberner (2014), Vivat Ars Lul-liana: Ramon Llull i la seva iconografia, Barcelona, Universitat Autònoma de Barcelona, p. 198.

42. Per exemple a l'obra de J. B. Laurens o a la d'Antoni Furió, que reproduïm. A. Furió SASTRE (1840), Panorama óptico-históricoartístico de las Islas Baleares, Palma, Imprenta de Pedro José Gelabert, lám. «Plaza de Cort».

43. Vegeu el document 4 en l'apèndix documental.

44. ARM, EU, 78, Extraordinaris Universitat 1667-1670, f. 12v.

45. B. Ferrà i Perelló (1899), «Techos artísticos en la isla de Mallorca (apuntes de mi cartera)». $B S A L$, núm. 229 (abril), p. 63.

46. M. Gambús Saiz, «La configuració arquitectònica...», op. cit., p. 101; C. BAuÇÀ DE MirAbÒ Gralla (en premsa), «La culminació escultòrica d'un voladís de fusta», a coord. E. González Gozalo, Història del voladís de la casa consistorial de Palma, Palma, Ajuntament de Palma.
47. B. Ferrà i Perelló (1899), «Techos artísticos en la isla de Mallorca (apuntes de mi cartera)», $B S A L$, num 229 (abril), p. 64.

48. M. Gambús Saiz i M. MassaNET GILI, Itinerarios arquitectónicos de..., op. cit., p. 101.

49. Les dades documentals $i$ l'estudi del dit sostre es publicaran pròximament.

50. M. Gambús SAIZ, «La configuració arquitectònica...», op. cit., p. 101.

51. Transcrit a ibídem, p. 102.

52. Transcrit a ibídem.

53. Vegeu el document 5 en l'apèndix documental.

54. El dit conjunt no existeix avui, ja que fou modificat amb la installació del rellotge actual.

55. ARM, AH, EU 82, Extraordinaris Universitat 1680-1684, f. 69r.-69v. Transcrit per M.

Gambús SAIZ, «La configuració arquitectònica...», op. cit., p. 103.

\section{E. GonzÁlez Gozalo (en} premsa), «Una aproximació al monument», a coord. E. GonZÁLEZ Gozalo, Història del voladís..., op. cit.

57. C. Bauçà de Mirabò GraLLA, «La culminació escultòrica...», op. cit.

58. C. Bauçà de Mirabò Gralla (2017), «La casa de l'Almoina i la Catedral de Mallorca: Un diàleg entre el Gòtic i el Renaixement», $B S A L, 73$, p. 61-79.

59. M. GambÚs Saiz, «Josep Gelabert...", op. cit., p. 112.

60. El brossenc era una classe de marès de gra gros i fàcil d'obrar, emprat per fer peces destinades a anar a cara vista. Vegeu $M$. Fullana I Llompart (1995), «Brossenc», a Diccionari de l'art $i$ dels oficis de la construcció, Mallorca, Moll, p. 77. 